\title{
The translational lag narrative in policy discourse in the United States and the European Union: a comparative study
}

\author{
Erik Aarden (1D) 1,5, Luca Marelli (iD) ${ }^{2,3,5}$ \& Alessandro Blasimme (iD) $4,5 \bowtie$
}

Whilst basic science rapidly produces new insights into the biological determinants of human health and disease, clinical innovation is often said to lag behind, as it fails to rapidly turn such knowledge into new tools for innovative patient care. This view of biomedical innovation constitutes a 'translational lag narrative', which is widely present in current research policy. This paper presents a qualitative content analysis of a corpus of documents $(n=28)$ issued by key policy actors in the domain of clinical translation between 2000 and 2018 in the United States and the European Union. The aim is to reconstruct how policy discourse articulates the translational lag narrative, and to analyze how the latter relates to specific sociotechnical imaginaries of progress and of the role of policymaking in their realization. The article identifies key impediments to clinical translation and highlights salient differences in the sociotechnical imaginaries of translation in the US and the EU. In the US, policy discourse around translation is mostly driven by the perceived need to re-instate linearity in the transition from knowledge-production to clinical innovation. In the European context, instead, the driving imaginary of the policy discourse around clinical translation has to do with constructing a distinctly European model of economic growth centered around the idea of a knowledge-based economy, thereby connecting policy stimuli for translation with broader political imaginations. This analysis elucidates how publicly staged narratives about science and technology in the biomedical field simultaneously contain state-specific visions of progress and statecraft.

\footnotetext{
${ }^{1}$ University of Klagenfurt, Klagenfurt, Austria. ${ }^{2} \mathrm{KU}$ Leuven, Leuven, Belgium. ${ }^{3}$ University of Milan, Milan, Italy. ${ }^{4}$ ETH Zurich, Zurich, Switzerland. ${ }^{5}$ These authors contributed equally: Erik Aarden, Luca Marelli, Alessandro Blasimme. ${ }^{凶}$ email: alessandro.blasimme@hest.ethz.ch
} 


\section{Introduction}

n June 2000, the first draft sequence of the human genome was announced. In his remarks on this historical accomplishment, President Clinton stated: "we are learning the language in which God created life" (The White House, 2000). This announcement initially fueled promises of rapid and revolutionary advances for medicine and health care (see e.g. Collins and McKusick, 2001). However, it soon started to be apparent that the breakthroughs in basic knowledge hardly translate automatically into therapeutic progress (Hayden, 2010; McElheny, 2010). To overcome what many perceived as a bottleneck in the transition from knowledge to innovation, the medical research community in the United States developed an action plan to bring advances in genomics to the clinic. This plan materialized in the so-called NIH (National Institutes of Health) Roadmap for Medical Research, which was first described in a Policy Forum in Science magazine by then-NIH director Elias Zerhouni (2003). The result of a year-long reflection involving the scientific community, government and the private sector, the NIH Roadmap stemmed from the realization that, as the newly sequenced human genome gave rise to a sense of promise and opportunity, "it also create(d) a series of challenges that will redefine (...) ultimately, how research leads to improvements in health" (Zerhouni, 2003, p. 63). The challenge ahead was to isolate and address "critical scientific gaps" (Zerhouni, 2003) that prevented the translation of discoveries into clinical applications. A Roadmap was considered necessary to bring the lagging pace of clinical translation up to speed with the "unprecedented" acceleration of scientific discovery (Zerhouni, 2003).

These efforts to remove "roadblocks to progress" (Zerhouni, 2003) form the latest expression of a long-standing concern in science policy-in the US and beyond. The concept of clinical translation has been around since at least the 1990s (Lindahl and Marincola, 2014) and the question of how research can be productive beyond the lab has an even longer, contested history. For much of the second half of the twentieth century, policymakers and innovation scholars alike have questioned the idea that scientific progress can in itself seamlessly lead to innovation (Guston, 2000; Godin and Lane, 2013; Elzinga, 2012). Nevertheless, the NIH Roadmap signifies more than just another instance of scientific and science policy actors fretting over the research-innovation nexus. The NIH Roadmap has propelled the creation of new policy agendas and funding programs, and has reconfigured research practices and steered collective priorities in biomedicine, both in the US and elsewhere (Vignola-Gagné, 2014). It has given rise to new journals, institutions and career paths (Nathan, 2005). 'Clinical translation' has become a widely circulating buzzword that is occasionally met with controversy (Jogalekar, 2011; Kahn, 2014), and is even considered to have brought about a new ethos for medical research "with the implicit value that science that can be translated into results is the best science, and everything else is second-tier" (Maienschein et al., 2008, p. 46). As such, translational medicine has become a discipline of its own, suggesting a new way of doing science more 'productively' (Pfotenhauer and Jasanoff, 2017). These perspectives are often expressed by way of diagnosing deficits in the pipeline from bench to bedside (Pfotenhauer et al., 2019). In particular, the discourse around the identification of, and response to structural deficits in biomedicine and innovation is shaped by a narrative centered around the metaphor of what we propose to call a 'translational lag'. This 'translational lag narrative'-which increasingly gained prominence since the launch of the NIH Roadmap in 2003-depicts the pace of clinical innovation (in terms of new drugs, new therapies, new diagnostic devices and the like) as disproportionately slower than the pace of biomedical knowledge-production. According to the translational lag narrative, basic science rapidly produces new insights into the biological determinants of human health and disease, but clinical innovation fails to deliver new tools to improve patient care at a comparable pace.

Expectations and promises of a better future for health and medicine are a key argument in favor of clinical translation (Wainwright et al., 2008; Vignola-Gagné and Biegelbauer, 2013). In that sense, public pronouncements of the importance of translation reflect established tropes of therapeutic promise and hope articulated in the context of biomedical research, and genomics in particular (Hedgecoe and Martin, 2003; Fortun, 2008; Martin, 2018). The discourse about translation does not exclusively refer to the internal organization of science. Rather, it combines an imagination of the promise of biomedical technology (DelVecchio Good, 2007) with the desire to restructure political and social spaces.

Comparing the framing of the translational discourse in the United States (US) and the European Union (EU), in this paper we show that different constructions of the translational lag cater to distinct 'sociotechnical imaginaries' (Jasanoff and Kim, 2015; Pfotenhauer and Jasanoff, 2017). Jasanoff defines these as "collectively held, institutionally stabilized, and publicly performed visions of desirable futures, animated by shared understandings of forms of social life and social order attainable through, and supportive of advances in science and technology" (Jasanoff, 2015, p. 4). Two specific sociotechnical imaginaries underpin the unfolding of translational policies in the two contexts. While to some extent similar failures in the path from discovery to application are diagnosed, remedies are framed differently with respect to different socio-political outcomes. Translational efforts, far from representing a mere internal shift in the biomedical sciences, are thus driven by, and produce transformative effects in, broader political and societal imaginaries within the US and the EU.

\section{Analyzing translational imaginaries}

The problem of clinical translation is most commonly represented by means of metaphors: 'cliffs' to be overcome, 'bottlenecks and 'roadblocks' to be removed, and 'gaps' between 'bench and bedside' to be 'bridged'. In its most daunting form, scientific knowledge needs to be carried across the "valley of death" that lies in the way of its clinical and commercial application (see e.g. Butler, 2008; Meslin et al., 2013). These metaphors project a temporal urgency onto clinical translation. This urgency is not uncontested in the biomedical literature however. Some commentators warn against an understanding of translation that operates only 'from bench to bedside', emphasizing how the feedback from the clinic to the lab also affects biomedical innovation (Marincola, 2003). Still others call for more careful distinctions between different phases of translation, such as, for example, between basic research and technology development; technical innovation and clinical application; or application of new technologies and measurable improvements in population health (Woolf, 2008; Khoury et al., 2007). Along similar lines, social scientists have also stressed that "[c]linical improvements are, in practice, far more complex and unpredictable and demand more recursive relations between bench and bedside" (Waldby, 2012, p. 183, see also Van der Laan and Boenink, 2015).

In this paper, we analyze how clinical translation is presented in US and EU policy discourse. The choice of this comparison was based on the fact that the US and the EU have been at the forefront of translational efforts worldwide, and that translation has acquired increasing prominence in science policy initiatives within these two regions. The US and the EU thus represent particularly salient case studies to probe the sociotechnical transformations triggered by efforts to advance translation. We 
used a qualitative content analysis of selected policy documents $(N=28$, see supplementary information: $S 1)$ to trace the particular formation of a translational discourse in the US and the EU. To identify relevant documents, we employed a purposive sampling strategy, targeting the main US and EU institutions endowed with science policy or funding prerogatives (e.g. NIH and the European Commission), as well as the key research infrastructures devoted to translation (e.g. NCATS in the US, IMI in the EU). We then searched the websites of these institutions, to identify key documents describing policies or initiatives intended to accelerate innovation in the biomedical domain. We included documents for the timeframe 2000-2018, with the aim of tracing how the translational discourse developed after the publication of the first draft of the human genome. We analyzed each of the identified documents in-depth, using an inductive, bottom-up coding approach that focused on how obstacles and solutions to translation were framed in the two contexts. On the basis of the coding, we classified 'impediments' and 'cures' into the broader categories featured in our analysis below. This approach was informed by the recognition, emerging from a preliminary analysis of translational policy documents and scientific articles, that translation is consistently conceptualized in terms of diagnosed deficits to be addressed in the "pipeline" from "bench" to "bedside". Following Hajer, we analyzed translational discourses by policy-makers as "ensemble[s] of ideas, concepts, and categories through which meaning is given to social [...] phenomena, and which is produced and reproduced through an identifiable set of practices" (Hajer, 2006; see also Wodak and Meyer, 2009; Fisher and Gottweis, 2012). This approach allowed us to examine "how the definition of a political problem relates to the particular narrative in which it is discussed" (Hajer, 2006). The social phenomenon at stake here is the perceived deficit in new therapies given the purportedly tremendous progress in basic research.

For the United States, we included documents issued by the National Institutes of Health (NIH) and its issue-specific National Center for Advancing Translational Science (NCATS), the Food and Drug Administration (FDA), and the National Academy of Medicine (NAM, known until 2015 as the Institute of Medicine, IoM). For the European Union, we drew on key documents by the European Commission-the main research funder at the EU-level-the European Parliament and the Council of the European Union, the European Medicines Agency (EMA), the Innovative Medicines Initiative (IMI), and the European Infrastructure for Translational Medicine (EATRIS). These institutions include some of the main actors formulating translational policies in both jurisdictions, as research financiers, regulators and administrators. While they are only some of the stakeholders involved in articulating the translational discourse, they allow us to focus on how policy actors articulate their views around the existing impediments to translation and the possible solutions to tackle them.

\section{Sociotechnical imaginaries of translation}

Framing translation in the United States. In this section, we present the results of our analysis of the policy discourse around clinical translation in the US context. The translational lag discourse was first articulated in the United States, gaining prominence under this label in the early 2000s. At the time, several government agencies tried to identify the causes and potential solutions for this problem. In our analysis, we found four major impediments that these agencies present as constitutive of the translational lag between basic biomedical knowledge and its clinical application.

The underdeveloped science of translation. A first layer of impediments to translation is located in the epistemic and technical content of biomedical research itself. In this respect, clinical translation is considered a scientific problem that "is poorly understood" (NCATS, 2013, p. i). Improvements in translation, or what the FDA calls the critical path of product development, thus require "greater activity in a specific type of scientific research" (FDA, 2004, p. 29). In addition, there is an important need "for technologies that positively change the translation process" (IOM, 2012, p. 18).

In particular, it is argued, there is a need for better product development 'tools'. The FDA, for example, makes this point explicit by stating that "translational research efforts will not yield the hoped-for results without an analogous focus on downstream development concerns". What is needed is research that "focuses on providing new tools and concepts for the medical product development process" (FDA, 2004, p. 7). They require making "the development process itself more efficient and effective and more likely to result in safe products that benefit patients" (FDA, 2004, p. 8). For the FDA in particular, these new tools include those that facilitate 'regulatory science', which is how the FDA describes its approach to evaluating medical products before they are allowed onto the market. In this context, the FDA argues, "developers are forced to rely on the tools of the last century to evaluate this century's advances" (FDA, 2004, p. 5). Developing regulatory science is hence predominantly imagined in terms of more efficient and up-to date regulatory appraisal, that will in turn lead to faster transition to the market. While it is reasonable to adapt regulatory science to the current state of the art of biomedicine, this appeal to catch up with what is new in the life sciences depicts regulatory oversight as lagging behind the cutting edge of research. At the same time, this framing pits innovation against regulation and attributes to the latter a potentially decelerating role with respect to clinical translation.

The absence of institutional and organizational capacities. Aside from scientific impediments, problems with clinical translation of scientific discoveries "can just as frequently be caused by organizational roadblocks" (NCATS, 2013, p. 20). These roadblocks are especially attributed to lack of collaboration between academia and industry and the absence of institutional formations that may facilitate such collaboration. Characterizing translation as, ideally, an "inherently collaborative and multidisciplinary" process (NCATS, 2013, p. 20), the US NCATS for instance identifies the lack of collaboration between public and private actors and the inadequate supply of an appropriately trained labor force as core concerns in the US context.

Public-private partnerships are seen as essential to "capitalize upon the respective strengths of government, academia, industry" (NIH, 2010, p. 7). While public and private institutions are considered to have complementary expertise, many policy documents identify hurdles. For example "academic and commercial organizations [are said to] have very different operating procedures, goals, and metrics of success" (IOM, 2012, p. 27). One potential solution is found in the ambition "that future TMAT [translational medicine and therapeutics] investigators are appropriately trained and sufficient in number" (NIH, 2010, p. 8). The key figure here is the hybrid clinician-scientist, who is considered "essential in clinical and translational research" (IOM, 2013, p. 9). In subsequent years, institutional support for clinician-scientists as translators, that is, as key-professional actors that operate to repair the translational gap, has grown considerably.

Moreover, the establishment of specialized institutions for translation is proposed, suggesting improvements in education and collaboration as solutions to organizational challenges. One of them, NIH's National Center for the Advancement of Translational Science (NCATS) is expected to develop a science of translation, "distinct in content, operations and culture" (NCATS, 2016, p. 1). 
NCATS is expected to achieve this through its "dual purpose' approach" that combines producing "potential new treatments for previously untreatable and devastating illnesses" with a broader aim to develop "new scientific and collaborative paradigms" to advance translation (NCATS, 2013, p. ii).

In keeping with long-held models of science policy in the US dating back to Vannevar Bush' science policy proposals in the 1940s (Bush, 1945) the translational discourse implicitly sees innovation as the linear result of knowledge transfer from the public to the private sector-as the site in which actual innovation happens. Stronger ties between academia and the private sector are therefore a condition to ignite such innovation potential, but the State has a role to play in creating the workforce that will make those ties possible and will operate to exploit them.

Regulatory deceleration. A third strand of impediments discussed across policy documents is the decelerating effect that regulation has on translation. This narrative is a common trope in innovation policy and is not unique to the biomedical domain. However, the regulatory pathway for therapeutic products and medical devices can be particularly time consuming and fraught with both technical and financial uncertainties (Kola and Landis, 2004; Paul et al., 2010). The regulatory requirements that new medical products need to fulfill before they are allowed onto the market and into the clinic are increasingly considered cumbersome and unfit for biomedical innovation (Pammolli et al., 2011). Employing a particularly creative play on alliterative metaphors, the FDA itself observes how "science alone is not enough to translate personalized medicine from microscope to marketplace", leading the agency to envisage "a series of regulatory policies and procedures to support its fruition" (FDA, 2011, p. 16). The Institute of Medicine, in turn, observes that a "significantly more effective and efficient regulatory system" is needed, since currently "the process is too expensive and too long" (IOM, 2012, p. 18). A key task for the FDA is therefore to improve "the transparency, consistency, predictability, and efficiency of regulatory requirements", while protecting "the public health" (FDA, 2014, p. 10).

Characteristic of the US approach to regulatory impediments is the development of what (in the particular context of support for small businesses) the FDA describes as "smart regulation" (FDA, 2014). FDA describes this in terms of the agency's ability to "attain the goal of protecting the public health while encouraging innovation", through "smart, sound, science-based regulation that imposes the most appropriate regulatory framework while minimizing unnecessary burden" (FDA, 2014, p. 9). While smart regulation can take various forms, it focuses on specific pathways that facilitate easier access of newly developed technologies to the market, or that allow products to become available to patients sooner.

Systemic impediments. The US policy discourse identifies a number of systemic impediments to efficient knowledge translation, namely: insufficient engagement with patients, the costs and complexity of the health care system, and the nature of global markets.

Lack of public engagement in research is considered to be an important "bottleneck" for translation (NCATS, 2016, p. 9). The Institute of Medicine, for example, states that "[t]he ultimate goal of translational research-to improve human health-requires meaningful community engagement across the entire spectrum of research from basic science to community and population health research" (IOM, 2013, p. 10). At the same time, an important and recurring argument for public engagement (e.g. through patient communities) is that it "builds trust and improves the quality of the research by enabling investigators to design studies measuring outcomes that are important to patients [while it] also provides researchers with better access to patients for studies" (NCATS,
2014, p. 19). The way policy documents in the US broach the subject of public participation thus reinforces the notion that supporting medical research and innovation is the primary aim of translational policies.

Drug markets and health care systems are often presented as "uncertain and challenging" (FDA, 2011, p. 4), thus posing further impediments to creating sufficient demand for innovative medical products. The Institute of Medicine in particular emphasizes the US health care system as an obstacle that contributes "to inconsistent health care quality, escalating costs, inequities in access, and shortcomings in improvement in population health outcomes" (IOM, 2013, p. 36). This claim points to problems with public accessibility, yet without necessarily turning public health into a core concern for translation. Instead, these concerns are primarily understood in terms of finding accessible and consistent markets for newly developed products, thus again suggesting that impediments for scientific advancements and commercial uptake are key in US translation policies.

A technical innovation imaginary. In US science policy circles, the core problem of translation is commonly described with the observation that while "basic biomedical knowledge is increasing exponentially, the gap between bench discovery and bedside application appears to be expanding" (FDA, 2004, p. 3). This diagnosis of the challenge of translation builds on discourses and policies that have supported the life sciences as a domain of commercial interest and potential economic growth since at least the 1980s (Cooper, 2008; Sunder Rajan, 2006). In this context, the state has played a central role, not only in terms of financing scientific research (Mazzucato, 2013), but also in terms of accommodating the industry's needs through regulation (Nik-Khah, 2014). In the context of pharmaceutical innovation, for example, Hogarth has explored the changing role of the FDA, which has increasingly developed permissive approaches to regulating the market admission of new products and fashioned itself as an actor with the task of contributing to innovation (Hogarth, 2015). This focus on commercialization of biotechnological innovation and translation aligns with the prominent role of technology and corporate actors in US biomedicine (Clarke et al., 2003). More broadly, market-oriented innovation has long served to legitimate public funding of research, with increasingly explicit measures of productivity being introduced over time (Guston, 2000). The emphasis in the US translational imaginary is thus on facilitating technological innovation, which should be developed and marketed primarily by private actors.

Framing translation in the European Union. In this section, we present the results of our analysis of the policy discourse around clinical translation in the context of the European Union. The translation discourse emerged later in Europe, and was in part informed by its increasing presence in the US. The European discourse on translation revolves around four impediments that are similar to those found in the US, yet these feed into a different imaginary of the relation between innovation, policy and society.

The 'European Paradox'. In the analyzed documents, innovation strategies in the EU are framed as having to confront what is presented as a quintessentially 'European paradox', that is, the contrast "between Europe's comparative advantage in producing knowledge, and its comparative disadvantage in turning that knowledge in innovation and growth" (EC, 2017, p. 7; cf. also Commission of the European Communities (1995). ${ }^{1}$ In turn, this paradox sets the challenge of "turn[ing] the high volume and quality of [European] science and research results faster and deeper into innovations which generate value for the economy and society" (EC, 2017, p. 8). 
Initiatives to accelerate translation are intended as means to repair a twofold lag: that between discovery and application, and also the competition gap between the EU and other innovation leaders like the US, Japan, and emerging countries such as China, Brazil, and India (see e.g. IMI, 2014, p. 13). More specifically, EU efforts at accelerating translation address an array of factors: the investment gap in pharmaceutical research and development $(\mathrm{R} \& \mathrm{D})$ vis-à-vis the United States and Japan (and prospectively China) (EC, 2006, p. 13; IMI, 2008, p. 17); "major bottlenecks" in $\mathrm{R} \& \mathrm{D}$ processes ("from discovery to delivery"), resulting in high attrition rates in the transition from pre-clinical to clinical research; and lack of adequate research and investment by pharmaceutical companies in areas of high public health concern but low return on investment (e.g. antibiotic resistance) (IMI, 2014 , p. 8). Efforts to address these concerns have resulted in a number of regulatory reforms and translational initiatives-most notably within the 7th Framework Program for EU research funding (2007-2013), which identifies translation as a key priority within the health domain (EP, 2006, p. 10). More recently, the Horizon 2020 research funding program (2014-2020) has been designed with the explicit intent of "taking great ideas from the lab to the market" (European Commission, n.d.). This articulation in particular assigns a characteristic innovation potential to research funded by the European Commission, and publicly presents the European Commission's investment in research as a propeller for economic growth within a knowledge-based economy model.

Fragmentation of the R\&I ecosystem. A second prominent strand of the European translational discourse revolves around the envisaged need to overcome the major impediment represented by the fragmentation of the EU research and innovation landscape. In this respect, the development of appropriate infrastructures and governance models geared to enhance the integration of public and private resources is considered essential. As it is argued in the Innovative Medicine Initiative (IMI) Strategic Research Agenda,

"Perhaps the biggest sociological divide in pharmaceutical sciences [is] the gap between academic and industry scientists. Put bluntly, the sooner academic and industry scientists destroy the stereotypes they hold for each other, the more likely that drug discovery and development will truly evolve to succeed in the 21st century" (IMI, 2008, p. 14)

In recent years, the EU has thus invested significant financial resources to stimulate more "effective public-private collaboration" (see e.g. EATRIS, 2014, p. 11), including through the IMI program. The existence of "market failures" in high-risk and capital-intensive sectors such as biomedical research is said to provide "a strong rationale for public support to private research and innovation activities". The preferred model is that of "structured partnerships [...] between the public and the private sector", rather than "public support to individual projects" (EC, 2013, p. 3). At a general level, the European Commission contends that, among their purported benefits, public-private partnerships support "a long-term, strategic approach to research and innovation", while enabling "innovative technologies to get faster to the market" (EC, 2013, p. 3, 4). More specifically, "bring[ing] key stakeholders together" is seen as key to "build Europe as a global leader in the delivery of healthcare solutions for medicines of priority to society" (IMI, 2014, p. 27). In spite of the considerable influence exerted by pharmaceutical industries and their trade association (EFPIA) on setting the agenda of the IMI program (Marelli and Testa, 2017) — the largest public-private partnership of its kind in the world-the role of the Commission is presented as a guarantee that public investment will serve the most pressing health needs of the European population.
In parallel, the EU has made it a priority to overcome the fragmentation of Member States' research and innovation systemsmost notably through the creation of a European Research Area (ERA) (EU Council, 2000, p. 4). In the green paper titled The European Research Area: New Perspectives, the European Commission contends that "fragmentation prevents Europe from fulfilling its research and innovation potential, at a huge cost to Europeans as taxpayers, consumers, and citizens" (EC, 2007, p. 6). Specifically, national and regional research funding programs and infrastructures are said to "remain largely uncoordinated [leading] to dispersion of resources, excessive duplication, unrealized benefits from potential spillovers, and failure to play the global role that Europe's R\&D capability would otherwise allow, notably in addressing major global challenges." (EC, 2007, pp. 6-7). Accordingly, since the 6th Framework Program, efforts at implementing the ERA, which have taken the shape of an applied policy approach (Dratwa, 2009), aimed at "overcom[ing] the fragmentation of efforts and policies, and ensuring that Europe makes the most of globalization in science and technology" (EC, 2007, p. 7). Notable efforts, in this regard, are represented by the establishment of pan-European infrastructures, such as the European Infrastructure for Translational Medicine (EATRIS), whose creation was first suggested as part of the European Strategy Forum on Research Infrastructures (ESFRI) Roadmap in 2006.

Regulatory impediments. Much like in the US, regulatory issues are at the forefront of the discourse on translation also in the EU. The European Medicines Agency (EMA) has initiated, over the last fifteen years, "a number of initiatives [...] with a view to accelerating patients' access to medicines that address unmet medical needs" (EMA, 2015). Notably, in recent years the EMA has revised guidance on 'accelerated assessment' and 'conditional marketing authorization', which are meant to reduce the timeframe for review of marketing-authorization applications and streamline the availability of medicines directed at seriously debilitating or life-threatening diseases. Besides, it has launched the Adaptive Pathways pilot scheme. The latter is meant to address "problems which have long existed in medicines regulation but have grown more acute in recent years", like the so-called "access-versus-evidence conundrum" (EMA, 2016), which relates to the trade-off between gathering robust evidence and ensure a swift commercialization of novel therapies. Despite these concerted efforts, however, there is still a perceived need, from the part of EU regulators, "to further reinforce regulatory and scientific support to foster development of new medicines addressing major public health needs" and "contribut[e] to a vibrant life science sector in Europe.” (EMA, 2015).

Moreover, in a rather distinctive way, the European regulatory discourse maintains a predominant focus on the fragmentation of the regulatory landscape across the different Member States as a major cause for the inefficiencies of the current regulatory regime. Such fragmentation is said to "make it in particular difficult to perform a given clinical trial in several Member States", with the issue being further exacerbated by the perceived need "to involve many, or all, Member States" in order "to include a sufficient number of patients" so as to "target more specific patient populations, such as subgroups identified through genomic information" (EP 2014, Recital 4). The lack of regulatory harmonization in clinical research is meant to be addressed by the recently approved Regulation 536/2014, aimed at accelerating review procedures through a single pan-European approval scheme (EP, 2014; de Miguel Beriain et al., 2020).

Systemic impediments. In addition to the aforementioned challenges, the European policy discourse on translation identifies further impediments in the European 'ecosystem' of research and 
innovation. As stated in the Strategic Research Agenda of IMI2 (the second phase of the Innovative Medicine Initiative), the "current healthcare ecosystem is not sustainable": complex and multi-directional efforts should be tailored to its amelioration (IMI, 2014, p. 7). The societal challenges that innovation is meant to overcome are "complex [...] and cannot be solved by any single European country, no matter how large it may be" (EC, 2018, p. 5). Similarly, "the creation of a knowledge-based society and economy in Europe" is staged as something that "cannot be sufficiently achieved by the Member States" alone (EP, 2006) - thus requiring the policy intervention of a large supra-national entity like the EU. In addition, the breadth of the gap to bridge to accelerate translation is said to require a "multidisciplinary, multi-stakeholder undertaking", hinging "not only [on] technical expertise and infrastructure, but also [on] insights into legal, intellectual property, regulatory, product development, and many other areas of expertise" (EATRIS 2015, p. 11). In this scenario, mobilization of the EU citizenry and involvement of a broader array of purportedly European experts and stakeholders is deemed a crucial requirement. This revolves around the involvement of major corporations-framed as European actors, in spite of their quintessentially global reach (Marelli and Testa, 2017) - and up-and-coming SMEs in programs like IMI. In addition, it takes the form of citizen and patient participation in R\&D processes, which is depicted as beneficial for the success of the translational endeavor. Their "increased participation [can] offer the opportunity to better understand the needs of each individual", while also casting "a different view, from [that of] the regulators, of the risks that they are prepared to take when weighed against the potential benefits of a new medicine" (IMI, 2008, p. 39).

An innovation-as-statecraft imaginary. Compared with the US discourse, which explicitly addresses the problem of 'translation' as such, in Europe the problem of translation is framed within the broader problem of innovation policy, with the two notions being presented as largely overlapping. In this sense, the translational discourse feeds off, and should be positioned within, the wider innovation discourse propelled by the launch of the Lisbon Strategy in 2000, which aimed to turn the EU into "the most competitive and dynamic knowledge-based economy in the world capable of sustainable economic growth with more and better jobs and greater social cohesion" (EU Council, 2000, p. 2). In the ensuing decade, the EU launched the Innovation Union, that is, one of the seven flagship initiatives of the Europe 2020 strategythe EU agenda for growth that followed in the footstep of the Lisbon Strategy (EC, 2010). Innovation Union has further reinforced the vision that "Europe's future is connected to its power to innovate: to turn great ideas into products and services that will bring growth to our economy and create jobs" (EC, 2014). In more recent times characterized by a politics of fiscal austerity, deflationary policies as well as fiscal consolidation, initiatives to prop up innovation have also been staged as prominent levers to sustain the competitiveness of the European biotech sector, and to drive "smart, sustainable, and inclusive" growth throughout the continent (EC, 2010, p. 2), so as to "innovate Europe out of the crisis" (EC, 2012, p. 5). Notably, this vision centered around the idea of a knowledge-based economy and economic growth is woven together with expectations on the further integration of the fragile European polity, forming a sociotechnical imaginary that is geared to shape the construction of shared European political identities and practices. Efforts at regulatory standardization, initiatives directed at harmonization of standards and infrastructures, and increased coordination of research and innovation policies, are all seen as necessary prerequisites for the economic and political integration of Europe itself (Callon, 2004).

\section{Discussion}

By taking a comparative approach to policy discourses on translation, we saw how different narratives and wider sociotechnical imaginaries of the social benefits of biomedical research and innovation are articulated. Both in US and EU policy documents, we identified impediments to clinical translation. While these impediments look quite similar in terms of considering scientific, organizational, regulatory and systemic issues, they form expressions of substantially different imaginaries of the social significance of biomedical innovation. These imaginaries can be clearly distinguished in several ways. On the one hand, they characterize the (technical) problem of translation and its social purposes differently. These differences link to the distinct role attributed to the state (or a supranational entity intending to act as state-like structure, the EU), both as an entity responsible for certain impediments and as one held accountable for repairing the lag. These views of the role of the state, in turn, are expressions of deeply seated understandings of the relation between science, government, and innovation in the EU and the US.

In the United States, translation is predominantly framed as the incapacity of science and the market to spontaneously produce expected innovations such as new cures or devices for patient care. The focus of the various translation initiatives we analyzed is to accelerate the generation of new products from biomedical research by removing regulatory obstacles and by incentivizing collaboration between government, academia and the private sector. This framing of translation should be read against the backdrop of the model that, under the inspiration of Vannevar Bush, shaped US science policy after WWII (Bush, 1945; Guston, 2000). In that model, so long as the state assured stable funding for basic research, market forces were deemed capable of capitalizing on accumulating scientific knowledge and delivering innovation at an acceptable pace. At present, however, the faith in spontaneous technological innovation in the biomedical domain has vanished, and, as a consequence, the role of the state has expanded to include a responsibility to actively remove regulatory and organizational bottlenecks and promote closer ties between science and the marketplace. Therefore, the sociotechnical imaginary of progress in science and innovation that sustains this policy narrative emphasizes a perceived need to re-instate linearity in the transition from knowledge-production to clinical innovation. As argued by Robinson (2019), and consistent with analyses of the role of marketmaking practices by governmental actors in neoliberal regimes (Mirowski, 2013), the attempt to re-instate linearity in science-tomarket translation promotes a market expansion in the health domain, by removing the barriers that prevent a steady flow of marketable technology developments.

On the other hand, in the EU the issue of translation has been distinctively framed in heavily political terms. This becomes clear when we consider that, while the US documents come predominantly from regulatory and scientific institutions, the EU corpus includes a significant number of documents stemming from political bodies, such as the EU Parliament and the European Commission. Moreover, as we have observed above, while the documents analyzed mostly target the issue of 'translation' as such in the US, this issue emerges in the EU mostly in relation to the broader discourse around innovation. In Europe translation is thus invested with an overtly political goal-as best conveyed by the 'Innovation Union' theme. Translational undertakings in Europe can be seen as part of broader attempts at constructing and consolidating shared pan-European identities and practices through sociotechnical endeavors such as infrastructure-building, harmonized governance, and the circulation of knowledges and artifacts. Therefore, while the European discourse is similarly grounded in a market failure model, it also sees possible solutions as an opportunity to further its broader statecraft ambitions 
directed towards reinforcing European collective aspirations for a knowledge-based socio-economic model. These efforts often address the still existing fragmentation among research and innovation systems and regulatory standards across Member States. "Europe's future" is said to be "connected to its power to innovate" (EC, 2014, p. 3). Bringing about this future is presented as a quintessentially European endeavor, that is, as a task that requires the enhanced involvement of the $\mathrm{EU}$ and as a problem that legitimizes the Union's very existence. In this light, the issue of fragmentation, highlighted as one of the main hindrances to European innovation, represents, in and of itself, a call for intervention for the $\mathrm{EU}$, since, "it is that said whole that is fragmented, and that is invoked and instituted 'as a pre-existing whole' by the very notion of fragmentation" (Dratwa, 2009, p. 91).

Despite the significant differences in how the translational lag, and policies for its repair, are formulated (see also Blümel, 2018), there are some noteworthy similarities in the directions these policies take. Various kinds of interventions that are proposed for the translational 'pipeline'-which include policy reforms, new funding streams, and changes to scientific institutions including universities and scientific journals-pursue application of scientific knowledge primarily in terms of commercial products that serve entrepreneurial interests (Robinson, 2017). Translation thereby reinforces broader trends in science policy, including the 'downstreaming' of fundamental research, an advancing 'audit culture' and emphasis on commercialization (Sunder Rajan and Leonelli, 2013). These developments have significant consequences for research practice, not only in terms of a growing intertwinement of 'basic' and 'applied' biomedical research, but also through an ever stronger need to consider legal and commercial implications of pursuing particular lines of research and development (Nelson et al., 2013; Keating et al., 2016; Gardner and Webster, 2016). Translation policies in different geopolitical contexts thereby contribute to a shared thrust towards a translational 'ethos' in science policy and practice (Maienschein et al., 2008).

The discourse around clinical translation thereby carries many of the hallmarks of reductionist understandings of innovation that have been widely discussed in critical innovation studies. In the context of translation, the 'linear model' of innovation continues to function as "a thought figure that simplifies and affords administrators and agencies a sense of orientation when it comes to thinking about allocation of funding to R\&D" (Godin, 2006, p. 659). Yet even critiques of this model within innovation policy and theory often maintain a simplified view of innovation. Innovation continues to be framed in narrow (technological) terms, with a rather superficial understanding of how innovation intersects with its social context (Godin and Lane, 2013). Innovation policy discourse often frames the state as a facilitator of market actors who are supposed to deliver new products and technologies. Such perspective however obscures the role of innovation policy as "also a means of governing society through national projects, through the rationalization and legitimation of state action, and through national identity-formation" (Pfotenhauer and Juhl, 2017, p. 83). Since translation policies aim to repair certain deficits in biomedical innovation, it is important to ask how these deficits are framed. The choice of particular problem definitions, and views of when and for whom innovation is 'successful' point to the essentially political nature of innovation in different (geo)political contexts (Pfotenhauer et al., 2019).

The distinct visions of translation set out in US and EU policy documents build on distinct science and innovation policies. Some of the most remarkable differences between translation policies in the United States and the European Union build on long-established science policy tropes. Science policy in the United States after World War II has been focused on the public funding of basic research that may produce innovations to be commercialized by private parties. The politics of science and knowledge in the European Union, instead, "were interwoven in the complex game of European integration" from its origins in the 1950s, and a fortiori since the EU actively began pursuing research and innovation from the 1980s onwards (Benner, 2018, p. 117). In the context of life science patents, Parthasarathy thus distinguishes a technology-focused "market-making" strategy in the United States, and a "market-shaping" strategy that explicitly considers broader social implications of technology development in the European Union (Parthasarathy, 2017). Parthasarathy emphasizes that patents hold wider sociopolitical significance than their common understanding as narrow legal categories would suggest. Our analysis suggests a similar observation about the politics of translation. It reflects a narrow focus on advancing marketable technology development or broader imaginations of how technology contributes to the shaping and consolidation of a political collective through scientific and technological practices and infrastructures (Misa and Schot, 2005), in how the respective political cultures of the United States and the European Union approach science and technology.

Despite those differences, however, translational discourse in the US and the EU also respond to shared trends and pressures. These include the changing role of the state, the collectivization of (corporate) risk associated with innovation and increasing geopolitical competition around science and technology (Benner, 2018).

\section{Conclusion}

On April 15, 2013, exactly 10 years after the completion of the Human Genome Project, Eric D. Green-then-director of NIH's Human Genome Research Institute-would respond elusively to the question regarding health benefit Americans had gained from this multi-billion dollar investment (Kolata, 2013). In attempting to ward off the cynical undertones of the question, Green timidly mentioned marginal gains in basic science (" $[\mathrm{w}] \mathrm{e}$ are understanding cancer and rare genetic diseases", Kolata, 2013) and clinical practice ("we have more informed ways of prescribing medicine because we first do genetic tests", Kolata, 2013). In a decade's time, the amazement of President Clinton for the mapping of the human genome-that we recalled at the beginning of this paper-had turned into a rather unsettling outlook, at least, compared to the expected outcome of considerable public investment. Such effects overflow the limits of discursive exchanges between a skeptical journalist and a leading geneticist trying to make the case for publicly funded research. Rather, they stem from often unspoken assumptions about the place of science and technology as constitutive elements of the body politic.

Science and technology, we have argued, are embedded in national (or supra-national, in the case of Europe) imaginaries of progress for which both government and science leaders can be held publicly accountable. The translational lag narrative casts such accountability in terms of new therapies and new drugs coming out of the pipeline of biomedical sciences. This locates science into broader visions of how scientific and technological developments contribute to social progress. We analyzed translational discourses in terms of a set of diagnoses and cures for what hinders biomedical innovation and thus impedes the attainment of certain national futures. We found these hindrances to be discursively located between basic science and its widespread clinical application, across different layers that ranged from technical and epistemic disconnects between the lab and the clinic, to inadequate organization, inappropriate regulatory preconditions, and wider systemic issues. In the US context, policy discourse is mostly driven by the perceived need to re-instate linearity in the transition from knowledge-production to clinical innovation. In the European context instead, the driving imaginary of policy discourse around 
clinical translation has to do with constructing a model of economic growth centered around the idea of a more interconnected and cohesive knowledge-based economy, thereby connecting policy stimuli to translation with broader political imaginations. Our analysis has therefore elucidated how publicly staged narratives about clinical translation are co-produced with state-specific sociotechnical imaginaries of progress and statecraft.

\section{Data availability}

Data used for the purposes of this article are available as supplementary information.

Received: 15 December 2020; Accepted: 31 March 2021; Published online: 06 May 2021

\section{Note}

1 For a critique of this narrative, cf. Dosi et al. (2009).

\section{References}

Benner M (2018) The new global politics of science. Knowledge, markets and the state. Edward Elgar, Cheltenham

Blümel C (2018) Translational research in the science policy debate: a comparative analysis of documents. Sci Public Policy 45(1):24-35. https://doi.org/10.1093/ scipol/scx 034

Bush V (1945) Science: the endless frontier. Trans Kansas Acad Sci 1903:231-264

Butler D (2008) Translational research: crossing the valley of death. Nature 453:840-842. https://doi.org/10.1038/453840a

Callon M (2004) Europe wrestling with technology. Econ Soc 33(1):121-134. https://doi.org/10.1080/0308514042000176766

Clarke A, Shim J, Mamo L, Fosket J, Fishman J (2003) Biomedicalization: technoscientific transformations of health, illness, and US Biomedicine. Am Sociol Rev 68(2):161-194

Collins F, McKusick V (2001) Implications of the Human Genome Project for medical science. JAMA 285(5):540-544. https://doi.org/10.1001/jama.285.5.540

Commission of the European Communities (1995) Green Paper on Innovation $\operatorname{COM}(95)$ 688. http://aei.pitt.edu/1218/1/innovation_gp_COM_95_688.pdf Accessed 27 Mar 2021

Cooper M (2008) Life as surplus: biotechnology and capitalism in the neoliberal era. University of Washington Press, Seattle

de Miguel Beriain I, Chortara T, Duardo-Sánchez A, Feeney O, Felzmann H, Fernández de Uzquiano E et al. (2020) An EU comparative analysis of the regulation of clinical trials supervisory bodies in the aftermath of Regulation 536/2014. Eur Public Law 26(2):307-330

DelVecchio Good M (2007) The medical imaginary and the biotechnical embrace. Subjective experiences of clinical scientists and patients. In: Biehl J, Good B, Kleinman A (Eds) Subjectivity: ethnographic investigations. University of California Press, Berkeley, pp. 362-380

Dosi G, Llerena P, Sylos Labini M (2009) Does the 'European Paradox' still hold? Did it ever? In: Delanghe M, Muldur U, Soete L (eds) European science and technology policy: towards integration or fragmentation? Edward Elgar, Cheltenham, pp. 214-236

Dratwa J (2009) Analysing Community policies. In: Delanghe M, Muldur, U, Soete L (eds) European science and technology policy: towards integration or fragmentation? Edward Elgar, Cheltenham, pp. 78-99

EATRIS (2014). Annual Report 2014. https://eatris.eu/wp-content/uploads/2017/ 05/ANNUAL-REPORT-2014.pdf. Accessed 27 March 2021

EATRIS (2015). Annual Report 2015. https://eatris.eu/wp-content/uploads/2017/ 05/ANNUAL-REPORT_2015.pdf. Accessed 27 March 2021

EC (2006). Creating an Innovative Europe. Report of the Independent Expert Group on R\&D and Innovation appointed following the Hampton Court Summit and chaired by Mr. Esko Aho. Luxembourg: Office for Official Publications of the European Communities, 2006. http://ec.europa.eu/investin-research/pdf/download_en/aho_report.pdf. Accessed 27 March 2021

EC (2007). Green paper. The European Research Area: New Perspectives. https://eur-lex. europa.eu/legal-content/EN/TXT/PDF/?uri=CELEX:52007DC0161\&from=GA. Accessed 27 March 2021

EC (2010). Communication from the commission. Europe 2020. A strategy for smart, sustainable and inclusive growth. available at: https://eur-lex.europa. eu/LexUriServ/LexUriServ.do?uri=COM:2010:2020:FIN:EN:PDF. Accessed 27 March 2021

EC (2012). The new Renaissance: will it happen? Innovating Europe out of the crisis. Third and final report of the European Research Area Board. http://aei.pitt.edu/ 46046/1/3rd\%2Derab\%2Dfinal\%2Dreport_en.pdf. Accessed 27 March 2021
EC (2013). Communication From The Commission To The European Parliament, The Council, The European Economic And Social Committee And The Committee Of The Regions. Public-private partnerships in Horizon 2020. https://eur-lex. europa.eu/legal-content/EN/TXT/PDF/?uri=CELEX:52013DC0494\&from=en. Accessed 27 March 2021

EC (2014). The European Union explained: Research and Innovation. http://www. dsps.unict.it/sites/default/files/files/research_en.pdf. Accessed 27 March 2021

EC (2017). Investing in the European future we want. Report of the independent High Level Group on maximising the impact of EU Research \& Innovation Programmes. http://ec.europa.eu/research/evaluations/pdf/archive/other_reports_ studies_and_documents/hlg_2017_report.pdf. Accessed 27 March 2021

EC (2018). Mission-Oriented Research \& Innovation in the European Union: A problem-solving approach to fuel innovation-led growth. https://ec.europa. eu/info/sites/info/files/mazzucato_report_2018.pdf. Accessed 27 March 2021

Elzinga A (2012) Features of the current science policy regime: Viewed in historical perspective. Sci Public Policy 39(4):416-428. https://doi.org/10.1093/scipol/scs046

EP (2006). Decision No 1982/2006/EC of the European Parliament and of the Council of 18 December 2006 concerning the Seventh Framework Programme of the European Community for research, technological development and demonstration activities (2007-2013). https://publications.europa. eu/en/publication-detail/-/publication/02345e40-a997-42c1-b6bfb392f266c586. Accessed 27 March 2021

EU Council (2000). Lisbon European Council 23 and 24 march 2000. Presidency conclusions. http://www.europarl.europa.eu/summits/lis1_en.htm. Accessed 27 March 2021

European Commission, (n.d.) What is Horizon 2020? https://ec.europa.eu/ programmes/horizon2020/en/what-horizon-2020. Accessed 27 Mar 2021

FDA (2004). Innovation, Stagnation. Challenge and Opportunity on the Critical Path to New Medical Products. http://wayback.archive-it.org/7993/20180125032208/ https://www.fda.gov/ScienceResearch/SpecialTopics/CriticalPathInitiative/ CriticalPathOpportunitiesReports/ucm077262.htm. Accessed 27 March 2021

FDA (2011). Driving Biomedical Innovation: Initiatives to Improve Products for Patients. http://www.celebrationofscience.org/assets/Uploads/DrivingBiomedical Innovation-ImprovingProductsforPatients.pdf. Accessed 27 March 2021

FDA (2014). FDA Strategic Priorities 2014-2018. https://wayback.archive-it.org/ 7993/20170405003823/ https://www.fda.gov/downloads/AboutFDA/Reports ManualsForms/Reports/UCM416602.pdf. Accessed 27 March 2021

Fisher F, Gottweis H (eds) (2012) The argumentative turn revisited: public policy as communicative practice. Duke University Press, Durham

Fortun M (2008) Promising genomics. Iceland and deCODE genetics in a world of speculation. University of California Press, Berkeley

Gardner J, Webster A (2016) The social management of biomedical novelty: facilitating translation in regenerative medicine. Soc Sci Med 156:90-97. https://doi.org/10.1016/j.socscimed.2016.03.025

Godin B (2006) The linear model of innovation. the historical construction of an analytical framework Sci Technol Hum Values 31(6):639-667. https://doi org/10.1177/0162243906291865

Godin B, Lane J (2013) Pushes and pulls: Hi(S)tory of the Demand Pull Model of Innovation Sci Technol Hum Values 38(5):621-654. https://doi.org/10.1177/ 0162243912473163

Guston D (2000) Between politics and science. assuring the integrity and productivity of research. Cambridge University Press, Cambridge

Hajer M (2006) Doing discourse analysis: coalitions, practices, meaning. In: van den Brink M, Metze T (eds.) Words matter in policy and planning. Netherlands Geographical Studies (NGS), Utrecht, pp. 65-74

Hayden E (2010) Life is complicated. Nature 464(Ap):664-667. https://doi.org/ $10.1038 / 464664 \mathrm{a}$

Hedgecoe A, Martin P (2003) The drugs don't work: Expectations and the shaping of pharmacogenetics Soc Stud Sci 33(3):327-364. https://doi.org/10.1177/ 03063127030333002

Hogarth S (2015) Neoliberal technocracy: explaining how and why the US Food and Drug Administration has championed pharmacogenomics. Soc Sci Med 131:255-262. https://doi.org/10.1016/j.socscimed.2015.01.023

IMI (2008). The Innovative Medicines Initiative (IMI) Research Agenda. Creating Biomedical R\&D Leadership for Europe to Benefit Patients and Society Available at: https://www.imi.europa.eu/sites/default/files/uploads/documents/ reference-documents/imi-gb-006v2-15022008-research-agenda_en.pdf. Accessed 27 March 2021

IMI (2014). The right prevention and treatment for the right patient at the right time. Strategic research agenda for innovative medicines initiative 2. https:// www.imi.europa.eu/sites/default/files/uploads/documents/About-IMI/ research-agenda/IMI2_SRA_March2014.pdf. Accessed 27 March 2021

IOM (2012). Accelerating the Development of New Drugs and Diagnostics: Maximizing the Impact of the Cures Acceleration Network: Workshop Summary. https://www.nap.edu/catalog/13452/accelerating-the-development-of-newdrugs-and-diagnostics-maximizing-the. Accessed 27 March 2021

IOM (2013). The CTSA Program at NIH: Opportunities for Advancing Clinical and Translational Research. https:/www.nap.edu/catalog/18323/the-ctsa-programat-nih-opportunities-for-advancing-clinical-and. Accessed 27 March 2021 
Jasanoff S, Kim S-H (eds) (2015) Dreamscapes of modernity. Sociotechnical imaginaries and the fabrication of power. University of Chicago Press, Chicago

Jasanoff S (2015) Future imperfect: science, technology, and the imaginations of modernity. In: Jasanoff S, Kim S-H (eds) Dreamscapes of modernity. sociotechnical imaginaries and the fabrication of power. University of Chicago Press, Chicago, pp. 1-33

Jogalekar AS (2011) Lost in translation. Curr Sci 101(12):1529-1530

Kahn J (2014) Privatizing biomedical citizenship: risk, duty, and potential in the circle of pharmaceutical life. Minn J Law Sci Technol 15(2):791-896

Keating P, Cambrosio A, Nelson N (2016) "Triple negative breast cancer": Translational research and the (re)assembling of diseases in post-genomic medicine. Stud Hist Philos Biol Biomed Scis 59(1):20-34. https://doi.org/ 10.1016/j.shpsc.2016.05.003

Khoury M, Gwinn M, Yoon P, Dowling N, Moore C, Bradley L (2007) The continuum of translation research in genomic medicine: how can we accelerate the appropriate integration of human genome discoveries into health care and disease prevention? Genet Med 9(10):665-674. https://doi.org/10.1097/ GIM.0b013e31815699d0

Kola I, Landis J (2004) Can the pharmaceutical industry reduce attrition rates? Nat Rev Drug Discov 3(8):711-716. https://doi.org/10.1038/nrd1470

Kolata G, (2013) Human genome, then and Now. N Y Times. http://www.nytimes. com/2013/04/16/science/the-human-genome-project-then-and-now.html Accessed 27 Mar 2021

Lindahl S, Marincola F (2014). Translational medicine. entry in the Encyclopedia Britannica. https:/www.britannica.com/science/translational-medicine. Accessed 20 April 2021

Maienschein J, Sunderland M, Ankeny R, Robert JS (2008) The ethos and ethics of translational research. Am J Bioeth 8(3):43-51. https://doi.org/10.1080/ 15265160802109314

Marelli L, Testa G (2017) "Having a structuring effect on Europe": the innovative medicines initiative and the construction of the European health bioeconomy. In: Pavone V, Goven J (eds) Bioeconomies. Life, technology and capital in the 21st century. Palgrave Macmillan, Basingstoke, pp. 73-101

Marincola F (2003) Translational medicine: a two-way road. J Transl Med 1(1):1-2. https://doi.org/10.1186/1479-5876-1-1

Martin P (2018) Genomic hope: promise in the bioeconomy. In: Gibbon S, Prainsack B, Hilgartner S, Lamoreaux J (eds) Routledge handbook of genomics, health and society. Routledge, London, pp. 79-89

Mazzucato M (2013) The entrepreneurial state. Debunking public vs. private sector myths. Anthem Press, London

McElheny V (2010) Drawing the map of life. Inside the human genome project. Basic Books, New York

Meslin E, Blasimme A, Cambon-Thomsen A (2013) Mapping the translational science policy 'Valley of death'. Clin Transl Med 2:14. https://doi.org/ $10.1186 / 2001-1326-2-14$

Mirowski P (2013) Never let a serious crisis go to waste: How neoliberalism survived the financial meltdown. Verso Books, London

Misa T, Schot J (2005) Introduction: Inventing Europe: technology and the hidden integration of Europe. Hist Technol 21(1):1-19. https://doi.org/10.1080/ 07341510500037487

Nathan DG (2005) The several Cs of translational clinical research. J Clin Investig 115(4):795-797. https://doi.org/10.1172/JCI24753

NCATS (2013) NCATS 2012-2013 Report. https://ncats.nih.gov/files/ NCATS_2012-2013_report.pdf. Accessed 27 Mar 2021

NCATS (2014) Report, https://ncats.nih.gov/files/NCATS_2014_report.pdf. Accessed 27 Mar 2021

NCATS (2016) NCATS Strategic Plan. Fall 2016 https://ncats.nih.gov/files/ NCATS_strategic_plan.pdf. Accessed 27 March 2021

Nelson N, Keating P, Cambrosio A (2013) On being "actionable": clinical sequencing and the emerging contours of a regime of genomic medicine in oncology. New Genet Soc 32(4):405-428. https://doi.org/10.1080/14636778.2013.852010

NIH (2010) Scientific Management Review Board. Report on Translational Medicine and Therapeutics. https://smrb.od.nih.gov/documents/reports/VOBR\% 20SMRB_Report_2014.pdf. Accessed 20 April 2021

Nik-Khah E (2014) Neoliberal pharmaceutical science and the Chicago School of Economics Soc Stud Sci 44(4):489-517. https://doi.org/10.1177/ 0306312717706110

Pammolli F, Magazzini L, Riccaboni M (2011) The productivity crisis in pharmaceutical R\&D. Nat Rev Drug Discov 10(6):428-38. https://doi.org/10.1038/nrd3405

Parthasarathy S (2017) Patent politics. Life forms, markets \& the public interest in the United States \& Europe. The University of Chicago Press, Chicago

Paul S, Mytelka D, Dunwiddie, Persinger C, Munos B, Lindborg S, Schacht A (2010) How to improve R\&D productivity: the pharmaceutical industry's grand challenge. Nat Rev Drug Discov 9(3):203-214. https://doi.org/ $10.1038 / \mathrm{nrd} 3078$
Pfotenhauer S, Jasanoff S (2017) Panacea or diagnosis? Imaginaries of innovation and the 'MIT model' in three political cultures Soc Stud Sci 47(6):783-810. https://doi.org/10.1177/0306312717706110

Pfotenhauer S, Juhl J (2017) Innovation and the political state: beyond the myth of technologies and markets. In: Godin B, Vinck D (eds) Critical Studies of Innovation. Alternative approaches to the pro-innovation bias . Edward Elgar, Cheltenham, pp. 68-94

Pfotenhauer S, Juhl J, Aarden E (2019) Challenging the "deficit model" of innovation: framing policy issues under the innovation imperative. Res Policy 48 (4):895-904. https://doi.org/10.1016/j.respol.2018.10.015

Regulation (EU) No 536/2014 of the european parliament and of the council of 16 April 2014 on clinical trials on medicinal products for human use, and repealing Directive 2001/20/EC

Robinson M (2017) Translational medicine: science, risk and an emergent political economy of biomedical innovation. In: Tyfield D, Lave R, Randalls S, Thorpe C (eds) The Routledge handbook of the political economy of science. Routledge, London, pp. 249-262

Robinson M (2019) The market in mind. The MIT Press, Cambridge

Sunder Rajan K (2006) Biocapital. The constitution of postgenomic life. Duke University Press, Durham

Sunder Rajan K, Leonelli S (2013) Introduction: biomedical trans-actions, postgenomics and knowledge/value. Public Cult 25(3):463-475. https://doi.org/ $10.1215 / 08992363-2144607$

The White House (2000) Text of remarks on the completion of the first survey of the Entire Human Genome Project. https://www.genome.gov/10001356/june2000-white-house-event/ Accessed 27 Mar 2021

Van der Laan AL, Boenink M (2015) Beyond bench and bedside: disentangling the concept of translational research. Health Care Anal 23(1):32-49. https://doi. org/10.1007/s10728-012-0236-x

Vignola-Gagné E, Biegelbauer P (2013) Translational research. In: Carayannis E (ed) Encyclopedia of creativity, invention, innovation and entrepreneurship. Springer, New York, pp. 1834-1843

Vignola-Gagné E (2014) Gaps, pitfalls and the valley of death: translational research and the reform of biomedical innovation. Dissertation, University of Vienna

Wainwright S, Michael M, Williams C (2008) Shifting paradigms? Reflections on regenerative medicine, embryonic stem cells and pharmaceuticals. Sociol Health Illn 30(6):959-974. https://doi.org/10.1111/j.1467-9566.2008.01118.x

Waldby C (2012) Medicine: the ethics of care, the subject of experiment Body Soc 18(3\&4):179-192. https://doi.org/10.1177/1357034X12451778

Wodak R, Meyer M (eds) (2009) Methods of critical discourse analysis. Sage, London Woolf SH (2008) The meaning of translational research and why it matters. JAMA 299(2):211-213. https://doi.org/10.1001/jama.2007.26

Zerhouni E (2003) The NIH roadmap. Science 302(5642):63-72. https://doi.org/ $10.1126 /$ science. 1091867

\section{Competing interests}

The authors declare no competing interests.

\section{Additional information}

Supplementary information The online version contains supplementary material available at https://doi.org/10.1057/s41599-021-00777-y.

Correspondence and requests for materials should be addressed to A.B.

Reprints and permission information is available at http://www.nature.com/reprints

Publisher's note Springer Nature remains neutral with regard to jurisdictional claims in published maps and institutional affiliations.

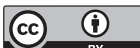

Open Access This article is licensed under a Creative Commons Attribution 4.0 International License, which permits use, sharing, adaptation, distribution and reproduction in any medium or format, as long as you give appropriate credit to the original author(s) and the source, provide a link to the Creative Commons license, and indicate if changes were made. The images or other third party material in this article are included in the article's Creative Commons license, unles indicated otherwise in a credit line to the material. If material is not included in the article's Creative Commons license and your intended use is not permitted by statutory regulation or exceeds the permitted use, you will need to obtain permission directly from the copyright holder. To view a copy of this license, visit http://creativecommons.org/ licenses/by/4.0/.

(C) The Author(s) 2021 